\title{
0 tropismo tropical dos malditos franceses
}

\author{
Camille Dumoulié
}

Resumo: Tropo, tropismo e tropical são termos que partilham a mesma raiz etimológica,
remetendo simultaneamente ao giro e ao movimento. A experiência limite das formas, da
linguagem e do afeto levou os "malditos" franceses a fazerem do "tropo", da figura retórica,
uma força do devir e da metamorfose que os colocou em contato com a vitalidade, ima-
ginária ou real, dos Trópicos.

Palavras-chave: Tropulsão; François Villon; Antonin Artaud; Lautréamont; Jorge Amado

Résumé: Trope, tropisme et tropical sont des termes qui ont la même racine étymologique, signifiant à la fois tour et mouvement. L'expérience limite des formes, du langage et de l'affect a poussé les "maudits" français à faire du "trope", de la figure de rhétorique, une force de devenir et de métamorphose qui les a mis en connexion avec la vitalité, imaginaire ou réelle, des Tropiques.

Abstract: Tropo, tropism, and tropical are terms that share the same etymological root, referring simultaneously to rotation and movement. The borderline experience of forms, language and affection led the "damned" Frenchmen to make of the "tropo", of the rhetorical figure, a power of becoming and of metamorphosis that put them in contact with the Tropics' vitality, imagined or real.

Keywords: Tropulsion; François Villon; Antonin Artaud; Lautréamont; Jorge Amado 
Os termos "tropo", "tropismo" e "tropical" têm todos a mesma raiz etimológica, isto é, o substantivo grego tropos, que significa "volta", "movimento", e o verbo trépô, que significa "girar", "dar uma direção".

Na retórica, um tropo é um recurso de linguagem que opera uma modificação no sentido usual de uma palavra. A metáfora, comumente definida como uma passagem do sentido próprio para um sentido figurado, constitui a figura emblemática do tropo. Este inclui, segundo o Littré, "certas formas de linguagem que dão ao discurso mais graça e vivacidade, deslumbramento e energia". Trata-se aí, como diziam Du Bellay e Ronsard, de "ilustrar" a língua "com comparações adequadas de descrições floridas, isto é, enriquecidas de passamanarias, bordados, tapeçarias e entrelaçamento de flores poéticas, tanto para representar a coisa quanto para o ornamento e o esplendor dos versos". ${ }^{1}$ Podemos observar o quanto essas flores poéticas entrelaçadas remetem às paisagens floridas dos trópicos. Mas o tropo não tem só uma função ilustrativa ou de ornamentação. Também serve para dar vivacidade, movimento, ao discurso em outras palavras, para deixar a vida penetrar na linguagem. Essa busca da vivacidade e da intensidade das figuras conduz às vezes a um desvio, uma transgressão da língua, e a palavra tropos também pode ser traduzida por "desvio".

$\mathrm{Na}$ astronomia, os trópicos são as duas linhas circulares em ambos os lados do equador que representam os limites dentro dos quais se inscreve o movimento do sol. Quando ele atinge a primeira linha, parece retornar para a segunda. Neste caso, como em muitos outros, os trópicos implicam uma experiência dos limites, e como um eterno retorno, uma força compulsiva que relança o movimento ao atingir o ponto-limite.

Essa identidade etimológica do tropo e do trópico será a base da minha fala, que pretende demonstrar que a experiência limite das formas, da linguagem e do afeto conduziu os "malditos" franceses a fazerem do tropo, da figura de retórica, uma força de devir e de metamorfose. O que os conectou com a vitalidade, imaginária ou real, dos trópicos. De tal forma que se pode até falar de um autêntico "tropismo".

Esse último termo, sempre segundo a etimologia, designa, na botânica e na etologia, o movimento das plantas e dos bichos, quando, por exemplo, são atraídos pela luz ou se dirigem para ela. Nathalie Sarraute foi quem o introduziu na literatura, particularmente no seu livro intitulado Tropisme (1939), para descrever "uma reação psicológica elementar pouco exprimível”.

1. RONSARD, Sonnets pour Hélène, II, pp. 60-64. 
Veremos então que existe um verdadeiro tropismo tropical dos "malditos" franceses (1), que se exprime através de uma poética vitalista dos devires que também é uma poética do excesso (2). Esse tropismo é um efeito daquilo que um dos últimos malditos franceses, Antonin Artaud, chama de "tropulsão", ou seja, uma pulsão excessiva de vida que é o outro lado da pulsão de morte. Assim, o desejo tropical deve se manter na condição de um tropismo, sem outro lugar de realização que não seja o espaço poético do tropo onde só a pulsão de morte se torna uma "tropulsão" de vida (3).

\section{O TROPISMO TROPICAL}

Quando Eliane Robert Moraes me deu o título desse belo projeto cuja iniciativa foi inteiramente dela, pensei numa frase de Artaud que, no final da vida, buscava inventar uma língua estrangeira dentro da própria língua francesa, que ele chamava "Daomé com dicção do Francês atual"2 e que ele definia como um "canto / cantarolado / secular / não litúrgico, não ritual / não grego / entre negro / chinês / índio / e francês Villon". ${ }^{3}$ Artaud, que tinha visitado os índios Tarahumaras no México e que, no final da vida, tinha desenhado o seu autorretrato como Inca, parecia procurar nos sotaques e nos ritmos tropicais um recurso para revitalizar a língua francesa e fazê-la delirar. Eu gostava de pensar que era possível traçar, entre o primeiro e o último dos "malditos" franceses, Villon e Artaud, uma espécie de linha tropical, um tropismo tropical. Um sonho um pouco louco, já que a América ainda não tinha sido descoberta quando Villon morreu, e os outros trópicos permaneciam ainda bem pouco explorados. No entanto, existe sim um François Villon dos trópicos. Encontrei-o no romance de Jorge Amado, Farda fardão camisola de dormir.

Esse romance, publicado em 1980, se passa nos anos 1940, depois da derrota francesa e durante a ditadura do Estado Novo no Brasil. Ele conta, de um modo heroico-cômico, a luta entre dois generais para alcançarem o posto na Academia deixado vago pela morte do poeta Antonio Bruno, vítima de um enfarte ao saber da tomada de Paris pelas tropas nazistas, no momento em que termina de escrever o título de seu último poema: "A camisola de dormir". Antes do final do romance, uma senhora

2. artaud, Antonin. Euvres Complètes, t. Xxi. Paris: Éditions Gallimard, 19, p. 151.

3. Id., Cahiers d'Ivry. Février 1947-mars 1948, t. 1. Paris: Éditions Gallimard, 2011, p. 150. 
da alta sociedade brasileira traz a um acadêmico uma coletânea de poemas eróticos que Bruno havia escrito em Paris em honra dela, prevendo uma publicação póstuma. Assim, contrapondo-se à derrota conjunta e grotesca dos dois generais postulantes à Academia brasileira, o romance relata a história de amor, ou melhor, de sexualidade tórrida, tropical, entre Bruno, quando era um jovem poeta brasileiro boêmio vivendo num pequeno sótão do Boulevard Saint Michel, e a rica senhora brasileira, que tinha ido a Paris para tentar esquecer o tédio da sua vida conjugal. Depois de um baile à fantasia onde ela se vestiu de Maria de Médicis pintada por Rubens, o jovem Bruno a leva para seu quarto e a possui furiosamente:

Na barra da manhã, Mariana se encontrou, Rainha pela metade, escrava da cintura para baixo, no leito do moço dançarino, vagabundo e gigolô, François Villon dos trópicos, como ele, gaiato, se intitulava a rir, após ter subido, bêbada e irresponsável, os seis íngremes lances de corroídos degraus, até a mansarda no sexto andar do Hotel Saint Michel. ${ }^{4}$ Assim teve início a bacanal, durou três meses. ${ }^{5}$

A não ser a vida de boêmio, Bruno não tinha muita coisa em comum com um "maldito" à la François Villon. No entanto, da mesma forma como o dionisismo tropical da sua juventude só foi revelado depois da morte, também postumamente, num teatro do Rio, foi lido um dos seus últimos poemas proibidos no Brasil, "Canto de amor para uma cidade ocupada", escrito em protesto contra a entrada dos alemães em Paris. E será outra amante sua, uma atriz, que, depois da representação, provocará o escândalo ao lê-lo no palco: "Impossível descrever a comoção do público, ninguém esperava, declamado do palco do Teatro Fênix, o poema maldito". ${ }^{6}$

Mas a ligação de Bruno com os poetas malditos se revela sobretudo na sua sexualidade tropical que se alimenta da fonte poética dos malditos franceses:

Três meses durante os quais Mariana se entregou e recebeu, recuperando os anos perdidos. Nada desejava senão estar na mansarda do poeta, do rapazola, do menino da Bahia que le bon Dieu de France lhe enviara pela mão fraterna de Silvia. Enchia-o de

\footnotetext{
4. Amado, Jorge. Farda fardão camisola de dormir. Rio de Janeiro: Record, 1980, p. 218.

5. Id., p. 219.

6. Id., p. 191.
} 
presentes, bebia-lhe palavras e versos. Beliscada, mordida, lambida, chupada, penetrada, cavalgada, cavalgando, cada noite uma estreia, uma nova sensação, os sabores tão diversos, as diferenças de buquê - e tudo em francês, língua na qual nenhuma palavra referente ao amor é obscena: le beau vit et le gentil con, la verge et la chatte, la rosette et les feuilles de rose, les nichons et les cuisses, la motte, le cul. Bruno dizialhe poemas eróticos de Baudelaire, Rimbaud, Verlaine, Apollinaire: "tes fesses lourdes comme des fromages de Hollande" e os praticava: "ma queue éclatait sous tes lèvres/ comme une prune de Juillet". Mariana aprendia e repetia com o acento das freiras do Des Oiseaux onde estudara francês: "mon cul séveille au souvenir/ d'une inoubliable caresse". Maravilha, adormecer nos braços de Bruno, despertar ao toque da língua exímia: "Ah comme c'est bon".

Cama de gigolô e de balzaquiana, de vagabundo e de bacante, gana e cio, fome e apetite. Não lhe bastando a poesia dos outros, Bruno compôs para Mariana uma coroa de sonetos dissolutos, onde cantou detalhe por detalhe seu corpo magnífico, dando rima e metro libertinos ao romance parisiense do François Villon da Bahia e da Maria de Médicis de São Paulo, vivido no Boul'Mich.?

É verdade que Bruno representa o exemplo do tropismo parisiense dos poetas tropicais, particularmente dos brasileiros; mas, ao mesmo tempo, revela um certo tropicalismo dos malditos franceses. Aqui apresentarei um breve panorama dessa linhagem, começando por Sade, para quem a natureza tem todas as características de uma natureza tropical, violenta e excessiva, que destrói para melhor recriar e transformar a matéria e as formas do vivo. Ela é, nessa acepção, uma instância ética e metafísica que ordena ao homem a prática de homicídio e a destruição como princípio vitalício de regeneração e metamorfose. Sade traz para o seu apogeu aquela experiência do sublime natural que, de Burke a Schiller e Nietzsche, conduz à visão dionisíaca do homem e da Natureza, que, ao longo do século XVIII, sempre faz referência à violência da natureza tropical.

Como lembrou Jean-Paul Manganaro, a viagem de Baudelaire no navio Paquebot-des-Mers-du-Sud, que o levou para os trópicos, alimenta mais do que um imaginário exótico: nutre um verdadeiro tropicalismo atestado em poemas como "Parfum exotique", "A une Dame créole" e, naturalmente, "A une Malabaraise", cuja

7. Id., pp. 219-220. 
figura epônima encontra sua encarnação em Jeanne Duval, a Vênus Negra, de um ponto de vista erótico, exótico e sexual.

Como eu descia pelos Rios impassíveis,

Não me senti mais guiado pelos sirgadores:

Índios gritando os fizeram alvos visíveis,

Tendo-os pregado nus aos seus postes de cores. ${ }^{8}$

Naqueles trópicos, o "barco ébrio" termina o seu périplo comercial e inaugura a sua deriva poética, ao invés do Rimbaud que cumpre a sua deriva mortal para os trópicos depois de terminar o percurso poético.

Desesperado pela decadência da cultura ocidental, Artaud pensou encontrar nas forças mágicas da terra mexicana o poder regenerador da vida e da poesia. A participação nos rituais dos índios Tarahumaras o submeteu ao que ele chama de "crivo da suprema expropriação", para melhor cumprir o seu destino sacrificial, em conformidade com o estatuto de poeta maldito que ele reivindicava.

\section{METÁFORA, METAMORFOSE E DEVIR}

Mas, para iniciar o segundo tempo do meu raciocínio, queria examinar o caso de um desses malditos, tão sintomático que se podia falar a seu respeito recorrendo a uma palavra de Bachelard, de um verdadeiro "complexo" tropical: trata-se de Lautréamont. Os trópicos não são, para ele, um destino sonhado, mas sim o lugar de uma origem. E, por duas vezes, o narrador dos Cantos de Maldoror faz lembrar isso, quando evoca "os gemidos graves do Montevideano", e quando escreve que "O final do século XIX verá seu poeta [...]; ele nasceu nas margens americanas, na foz do Rio da Plata". ${ }^{\circ 0}$ Os lugares que assombram Maldoror são inumeráveis e às vezes impossíveis de situar, mas, seja em Paris, no meio do oceano ou no grande Norte ártico, seguindo as metáforas e comparações, o espaço é atravessado por fulgores tropicais. Assim, Maldoror e o com-

8. Rimbaud, Arthur. "Le Bateau ivre", "O barco ébrio", tradução de Oscar Gama Filho.

9. LAUtrÉAmont, Les Chants de Maldoror et autres cuvres. Paris: Booking International, 1995, p. 18.

10. Op. cit., p. 50. 
panheiro vão pairando no céu como "dois condores dos Andes [...] entre as camadas atmosféricas na vizinhança do sol", para fugir da terra, esse "penico rochoso onde se esforça o ânus trancado de cacatuas humanas". ${ }^{12}$ Mais adiante, "os ventos estridentes de equinócio [...] mugirão como as manadas gigantes dos búfalos da pampa".13 $\mathrm{O}$ narrador descreve depois a "caça ao negro fugitivo". ${ }^{14}$ De maneira geral, a flora e o bestiário são povoados por camaleões, orangotangos e outras espécies tropicais. Falei de flashes na medida em que, para Lautréamont, metáforas e comparações não são imagens mas sim vetores de energia, blocos de realidade que participam do fenômeno de metamorfose no qual são incluídos o homem, o animal e o vegetal.

Esse vitalismo tropical está, sim, no centro do complexo de Lautréamont, tal como o analisa Bachelard: "É o excesso da vontade de viver que deforma os seres e que determina as metamorfoses". ${ }^{15}$ "Como o movimento é o que importa, as metáforas são sempre tomadas na sua base animal, e nunca se sabe em que espécie do reino animal o desejo vai se efetuar [...]", "Naturalmente, não se trata, para Lautréamont, de encontrar transcendências evaporadas; nossas fronteiras são vitais, biológicas; temos portanto que ultrapassá-las vital e biologicamente". ${ }^{17}$ Aquele poder de metamorfose da metáfora é o apanágio do que Bachelard chama de "poesia primitiva". ${ }^{18}$ Mas "a primitividade na poesia é tardia": 19 é preciso abrir mão dos livros e dos mestres para inventar uma "poesia projetiva", energética e dinâmica. Ela exprime a ligação vital que une biologia e poesia, e revela que "o ser vivo tem um apetite de formas pelo menos tão grande como um apetite de matéria". ${ }^{\circ 0}$ Tornando sensível a continuidade original entre metáfora e metamorfose, Lautréamont "nos ajuda a desenhar essa linha de força que representa o esforço estético da vida". ${ }^{21}$ "Ao longo dessa linha de força, deve-se sentir a

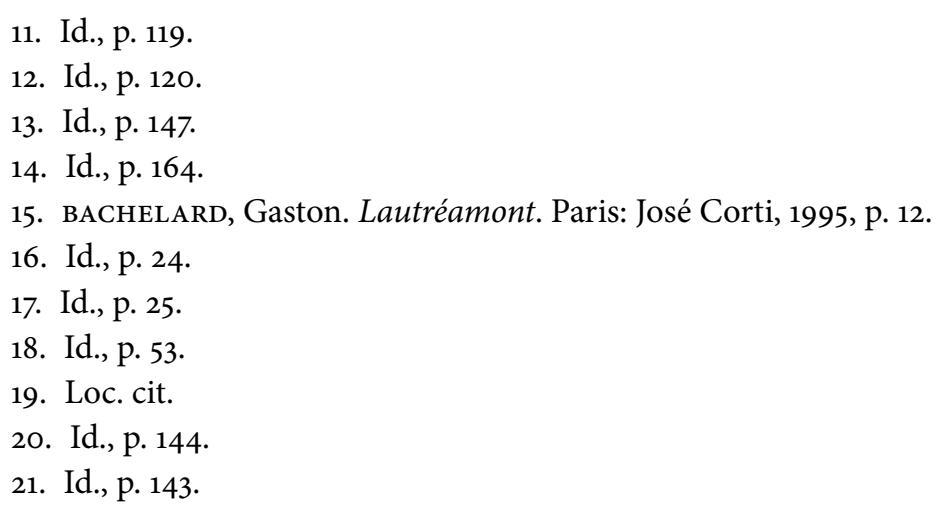


riqueza da matéria viva, que é a vida ardendo, a vida precisa que ataca, a vida sonhadora que brinca e que pensa". ${ }^{22}$ Dessa maneira, a obra de Lautréamont ilustra uma função essencial da poesia moderna, cujos precursores incluem Baudelaire, e que "prova que o homem quer um devir [...]. Algumas poesias se concentram na transformação, outras na transfiguração. Mas o ser humano, por meio do verdadeiro poema, deve sempre sofrer uma metamorfose. A função principal da poesia é nos transformar". ${ }^{23}$

A meu ver, esse poder de metamorfose é o centro poético - no sentido forte e etimológico do verbo poiein - do tropismo tropical dos poetas malditos. E ele faz a ligação com os poetas "tropicais". Para citar apenas umas obras, quero evocar Meu tio o Iauaretê de Guimarães Rosa; vários textos de Clarice Lispector, incluindo prioritariamente Perto do coração selvagem; ou o conto "Alguém dorme nas cavernas" de Rubens Figueiredo, um conto que pertence à coletânea $O$ livro dos lobos, ou ainda, para citar o repertório linguístico francês, L'Esclave vieil homme et le molosse de Patrick Chamoiseau.

Porém, também se podem mencionar esses outros poetas do espaço e dos devires que são os capoeiristas. Como já tentei mostrar, ${ }^{24}$ a capoeira, essa invenção dos escravos negros do Brasil, é uma física dos devires animais pondo em jogo uma ontologia que se contrapõe à metafísica ocidental do Ser. Mais profundamente, essa concepção da phusis própria da capoeira encontra a sua fonte na cosmologia e nos rituais do Candomblé, que consistem em invocar os deuses da África para aceder ao devirdeus, devir-criança, devir-animal. Enfim, também incluo entre os poetas tropicais os povos da Amazônia cuja concepção do mundo e da natureza foi descrita por Eduardo Viveiros de Castro 25 como uma verdadeira "filosofia canibal", em que ética e física passam pela experiência do devir-animal. Poetas, eles os são todos, porque a experiência dos devires e das metamorfoses implica uma invenção poética e uma revolução linguística ou semiótica.

\footnotetext{
22. Loc. cit.

23. Id., pp. 104-105.

24. DumouliÉ, C. “A capoeira, uma filosofia do corpo", Revue Silène, 16 dez. 2006, http://www.revue-silene.com/f/index.php?sp=liv\&livre_id=67 \& "Saudade do Berimbau. Nota musical em anexo a 'A capoeira, uma filosofia do corpo"', Revue Silène, 25 maio 2012, http://www.revue-silene.com/f/ index.php?sp=liv\&livre_id=168.

25. Por exemplo em Araweté: os deuses canibais. Rio de Janeiro: Jorge Zahar/Anpocs, 1986.
} 


\section{A TROPULSÃO TROPICAL}

Aquela energia que alimenta o tropismo tropical, que faz do tropo um instrumento de metamorfose e de devir, que conduz a uma subversão da língua sob o impulso de uma espécie de excesso de vida fazendo explodir o enquadramento linguístico, pode ser chamada, para utilizar a expressão de Artaud, de "tropulsão". ${ }^{26}$ A pulsão, impulso cego do vivo, que obedece ao tempo do eterno retorno, ou seja, da compulsão de repetição, como o Sol que nunca deixa de girar e voltar entre os trópicos, é sempre "trop", para dizer em francês, ou, traduzindo, é sempre demais, para os seres vivos, e sobretudo para o ser humano que só sobrevive dentro do enquadramento da linguagem e da cultura. O impulso transbordante de vida da pulsão é destrutivo para o indivíduo e pode ser identificado com a pulsão de morte. No entanto, alimenta o poder irrefutável, irreconciliável e vulcânico do sujeito. De certa maneira, ele entrega a sua energia para o nada. Daí que Artaud possa afirmar: "Eu sou... uma tropulsão".

A pletora vital e destrutiva da natureza tropical retrata o paraíso perdido de um sujeito explosivo que estaria finalmente afinado com o poder da metamorfose da pulsão que movimenta o vivo, num interminável "morra e advenha!". A finalidade de todos os devires - animal, mulher, criança, negro, índio - é o que Deleuze e Guattari chamam de "devir-imperceptível" - definição eufemística da pulsão de morte. "Maldito" é quem assume o seu destino sacrificial tornando-se o suicidado voluntário da sociedade. O tropismo tropical é uma das expressões desse desejo de morte gloriosa, primitiva, sublime, dionisíaca, em que o gozo último da carne corresponderia ao gozo original do verbo poético. Neste sentido, os trópicos são o "Real", no sentido lacaniano do termo, ou seja, o impossível, o inominável, onde acaba a poesia: fim da vida poética de Rimbaud na Abissínia; desfalecimento de Artaud nos Tarahumaras que o teriam enfeitiçado; morte espiritual de Gauguin no Taiti. O "barco ébrio" naufraga nos trópicos, mas vive eternamente no poema que leva o sujeito poético (autor e leitor) na deriva de um devir-tropical, onde ele percorre os elementos, a fauna e a flora até um devir-imperceptível que o poema torna eterno.

26. O termo "tropulsion" vem de um texto de 1947 em que Artaud escreve: "Je suis un corps/ une masse / un poids/ une étendue/ un volume" etc., uma lista que termina por "une tropulsion", in: Antonin Artaud, Euvres, Paris, “Quarto”, Gallimard, 2004, p. 1492. 
Eu choquei-me, sabei vós, com incríveis Floridas

Mesclando flor com olhos de pantera e humanas

Peles! ${ }^{27}$

Poeticamente, vejo nesses versos a ligação entre as "descrições floridas, isto é, enriquecidas de passamanarias, bordados, tapeçarias e entrelaçamento de flores poéticas" que evocava Ronsard a propósito dos tropos que ilustram a língua, e o devir-onça, jaguar ou lobo que já foi evocado. Em outras palavras, o tropismo tropical implica uma resistência à tentação exótica dos trópicos. "Não se vai embora", como dizia Rimbaud neste trecho de Une Saison en enfer onde ironicamente evocava o retorno da impossível viagem nos trópicos:

Regressarei, com membros de ferro, pele sombria, ar furioso: pela minha máscara, me julgarão de raça forte. Terei ouro: serei ocioso e brutal. Mulheres cuidam desses ferozes enfermos que voltaram dos países quentes. Me envolverei nos assuntos políticos. Serei salvo.

Agora sou maldito, tenho horror à pátria. O melhor é dormir bem embriagado na praia. Não se vai embora. ${ }^{28}$

O tropismo tropical é um efeito da embriaguez do litoral cuja borda nunca é ultrapassada, tal como o Sol que não ultrapassa as linhas dos trópicos. Atesta uma experiência dos limites que dá à função trópica da linguagem o seu valor e sua força de real. O tropismo tropical é, portanto, um fenômeno essencialmente poético, implicado dentro do tropo, e pelo tropo. Os limites da figura poética contêm o excesso transgressivo da pulsão que penetra a linguagem. Mas essa figura poética só tem valor poético se, na sua borda, tiver contato com o real. Assim, a literatura, como escrevia Lacan no seu texto "Lituraterra", é um fenômeno de litoral: ela fica circunscrita no literal, mesmo quando tem o seu limite como alvo, de maneira que "a escritura é, no real, o ravinamento do significado", ${ }^{29}$ Lacan

27. RIMBAUd, Arthur. "O barco ébrio", op. cit.

28. Id., Une saison en enfer. Paris: Le livre de Poche, 1998, p. 52.

29. J. Lacan, D’un discours qui ne serait pas du semblant, Le séminaire, livre xvirI. Paris: Le Seuil, 2006, p. 122. 
explica: "O que se evoca de gozo até que se rompa um semblante, é isso o que no real apresenta-se como ravinamento". ${ }^{\circ}$

Todos aqueles ravinamentos, todos aqueles sulcos, que as chuvas tropicais vão escavando no solo do Brasil, o que serão, senão convites para produzir significantes capazes de ravinar, de escavar, o significado? Tendo eu atendido a esse convite, retorno ao Brasil muitas vezes para acolher as chuvas tropicais. Mas temo não ter produzido significante algum suscetível de ravinar o significado. É por esta razão que eu não sou um maldito. Ainda não...

Tradução do francês para o português: Simon Berjeaut.

Camille Marc Dumoulié é professor de literatura comparada da Universidade de Paris OuestNanterre-La Défense, onde dirige o centro de pesquisa "Literatura e Poética Comparadas". É diretor editorial da revista Silène, da coleção "Literatura e Ideia” (Editions Desjonquères, Paris) e da coleção "Literatura e Poética Comparadas" (Presses Universitaires de Paris Ouest-Nanterre-La Défense)0. Publicou livros sobre Nietzsche, Artaud, Don Juan, literatura e filosofia, e no Brasil: O desejo (Vozes, 2005).

30. LaCAN, J. “Lituraterre”, Autres écrits. Paris: Le Seuil, 2001, p. 17. 